mass, gaseous matters which are given off when the rock is heated. This is especially true of lavas of a glassy character, which when fused have been shown to swell up into masses of pumice of many times the dimensions of the glass from which it is formed. $M$. Albert Brun, of Geneva, has collected and analysed the gases given off in such cases, and finds them to be nitrogen, ammonia, chlorine, hydrochloric acid, carbonic acid, and various hydrocarbons. Reasoning from these and other observations, he has been led to the conclusion that steam, instead of playing the most important part in volcanic eruptions, must be regarded, in many cases at least, as only an adventitious and accidental accompaniment of them. He has certainly shown grounds for the more thorough investigation of the nature and composition of these mixed gases, which, as recent studies have shown, play such an all-important part in volcanic outbursts.

But in addition to the more exact and systematic studies which have been made of the great volcanic eruptions in recent years, there is another class of researches which have supplied evidence of at least equal value concerning the nature and origin of these phenomena.

The study of rocks in thin sections under the microscope has shown that the two classes of rocks known as "plutonic" and "volcanic" respectively are essentially identical, and pass into one another by insensible gradations. Great areas of crystalline rocks ("batholites") and lake-like intrusions of similar materials ("laccolites"), lying in the midst of sedimentary and other rocks, were probably the roots of the volcanoes of previous periods in the earth's history. In these cooled reservoirs we may study the changes which have taken place in the magmas that have supplied the old volcanic vents, and-inverting the Lyellian principle-we may reason concerning the processes which must now be going on beneath existing volcanic vents from what we can prove to have taken place beneath those of former geological periods. Nor are there wanting examples of ancient volcanoes, dissected by the scalpel of denudation, which illustrate the intimate connection which exists between the plutonic and volcanic rock-masses.

The author of the memoir before us is well known to geologists by a number of valuable memoirs dealing with the evidence of changes which must have taken place in the great underground reservoirs of igneous rocks. These he has had the opportunities of investigating while engaged as a Canadian member of the International Boundary Surveys. More recently, he has had the opportunity of making a detailed investigation of the phenomena exhibited in the Hawaiian volcanoes. His outline of "a general working theory of vulcanism" is the result, as he tells us, "of the writer's studies in the Hawaiian Islands in I909, but many of the chief conclusions are founded on his field-work in plutonic geology, as well as on the geology of many ancient volcanic formations."

That the hypotheses he now formulates are of a somewhat speculative character, and that many of his conclusions are more or less tentative; Mr. Daly fully admits; but that, nevertheless, his memoir is an important contribution towards the solution of a very difficult problem everyone will agree. He summarises his suggestions as a "substratum-injection hypothesis," believing that the surface phenomena can best be accounted for by abyssal injections of a deepseated basaltic magma through an acid substratum of granitic or gneissic rocks everywhere underlying the sedimentary formations. But in elaborating his theory the author is led into a number of discussions NO. 2 I94, VOL. 88 ] of points of extreme interest and importance, and, even if his main conclusions are rejected, these subsidiary discussions retain their suggestiveness and vilue.

It is admitted by the author that the conditions leading to his "abyssal injections" "form a subject of great theoretical difficulty"; he apparently accepts the view that the high temperatures underground are due to the earth being a cooling globe, although he admits the influence of various chemical reactions in augmenting, locally, these high temperatures. The chief argument in favour of the view that the earth's interior is in a highly heated, if not molten, condition is, of course, derived from the fact that observations made in mines, tunnels, wells, and bore-holes everywhere indicate a progressive rise in temperature as we go downwards. Nevertheless, the most recent observations of underground temperatures have revealed such startling discrepancies between the results obtained in different areas--discrepancies that, it seems, are quite incapable of being explained by differences in the conductivity of rocks and similar causes - that the argument for a "molten globe" based on underground temperatures loses much of its force, and with it must go the estimates of the earth's age that have been based upon it. In these circumstances, the thoughts of geologists turn, not unnaturally, to the great revelation of radio-activity as a source of heat, for here may possibly be found the means of removing, to some extent at least, the "theoretical difticulties" which, the author admits, still beset the explanation of those deep-seated actions for which he argues.

J. W. J.

\section{SPANISH OBSERVATIONS OF BROOKS'S COMET (I9IIC).}

BROOKS'S comet has recently been a conspicuous object, and no doubt a great number of valuable observations have been made, both photographically and visually, at most of the observatories in the northern hemisphere.

Some very interesting records have recently been received from Señor F. Iniguez, the director of the Madrid Observatory, and not only do these include photographs of the comet itself, but an excellent spectrum accomnanied by a list of the wave-lengths of the bands recurded.

The photograph showing the form of the comet was secured on September 28 , with a 6-inch Grubb doublet, during an exposure of one and a quarter hours ( $9 \mathrm{~h}$. $\mathrm{I}_{5} \mathrm{~m}$. to $\mathrm{roh} .3 \mathrm{om}$.), the comet then being of the second or third magnitude. This photograph is reproduced here (Fig. I), the scale being $\mathrm{I} \mathrm{mm}$. to 5 minutes of arc. On this date the tail stretched to a distance of $\mathrm{r}_{5}$ degrees, and consisted of delicately fine interlacing filaments; the nucleus with its surrounding nebulosity measured $2 \mathrm{I}$ minutes in diameter. Spectroscopic observations were made visually with a slit spectroscope, and photographs were secured with the Grubb photographic equatorial, having an objective prism of $20 \mathrm{~cm}$. aperture and $20^{\circ}$ refracting angle. These have shown the spectrum to consist of seven images of the nucleus. The visible bands are the three situated at the red end of the spectrum, and these form three distinct spectral bands, while the sixth is composed of fine lines. The seventh appears double, although its components are not well defined and were measured as single.

The wave-lengths have been determined by Señor Iniguez from four plates taken on September I9, 20 , and 26. The three visual monochromatic images of 
the nucleus are $\lambda 555,514$, and 472 . The fourth band is made up of the lines $\lambda 440,434$, and 432, and the wave-length of the fifth is $\lambda 423$. The sixth band he finds to be composed of the lines $\lambda 4^{10}, 407,405,404$, and 402 , while 388 he gives as the wave-length of the seventh band. By using a prismatic camera, the spectrum of the comet's iail has also been secured, but because of its faintness only monochromatic images of the tail in the three visible bands were

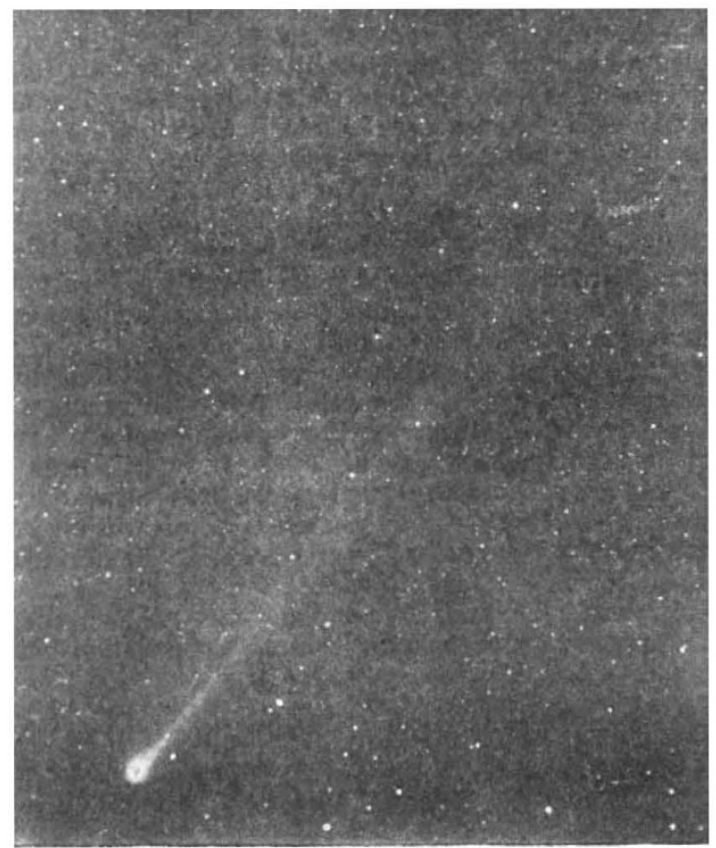

FIG. I.-Brooks's Comet as photographed on September 28 at the Madrid Observatory with an exposure of $x \frac{1}{4}$ hours.

recorded. The whole length of the spectrum indicates the presence of a faint continuous spectrum. This spectrum was secured on the night of September 26 with an exposure of two hours (gh. to IIh. G.M.T.). Besides a paper print of this spectrum, a drawing with a scale of wave-lengths also accompanies the communication. This drawing is reproduced here (Fig. 2), but the violet has been placed on the lefthand side to conform with the general adopted procedure. the chief carbon bands being strongly developed, it is very probable that the Madrid spectrum represents bands and lines of the same substances. No doubt in the near future spectrum observations, both photographic and visual, made at other institutions, will be soon forthcoming, so it will be interesting to see if the same explanation of the origin of the bands is corroborated.

W. J. S. LOCKYER.

\section{CONFERENCE ON THE THEORY OF RADIATION.}

A VERY successful meeting was held in Brussels A from October 29 to November 4, to discuss the present position of the theories of radiation and of molecular theory in general. The following were present at the meeting:-Profs. H. A. Lorentz, Kamerlingh Onnes, W. Nernst, M. Planck, Rubens, Sommerfeld, W. Wien, Warburg, Brillouin, Mme. Curie, Langevin, Perrin, Poincaré, Einstein, Hasenöhrl, Martin Knusden, J. H. Jeans, and Rutherford, while Dr. Goldschmidt, of Brussels, Dr. de Broglie, of Paris, and Dr. Lindemann, of Berlin, acted as secretaries.

The inception of this "conseil scientifique" was due to Mr. Ernest Solvay, of Brussels, who very generously offered to defray the expenses of the conference and the cost of publication of the papers and discussions contributed at the meeting. The members were the guests of Mr. Solvay at the Hotel Metropole, and with the exception of one meeting at the Physiological Institute, founded by Mr. Solvay, the meetings took place in one of the reception-rooms of the hotel. The arrangements of the meeting were under the charge of Dr. Goldschmidt, who was indefatigable in looking after the comfort of the visitors. Prof. H. A. Lorentz was president of the "conseil scientifique," and the success of the meeting was due in large measure to his able management.

The following papers were read before the congress:-Sur l'application au rayonnement du théorème de l'équipartition de l'énergie, by Prof. $\mathrm{H}$. A. Lorentz; a short communication in the form of a letter from Lord Rayleigh; the kinetic theory of specific heats, by Prof. J. H. Jeans; die Gesetze der Wärmestrahlung und die Hypothese der elementaren Wirkungsquanten, by Prof. Max Planck; die Bedeutung des Wirkungsquantums für unperiodische Molekularprozesse in der Physik, by Prof. Sommerfeld; zum gegenwärtigen Stande des Problems der spezifischen Wärme, by Prof. Einstein; Anwendung der
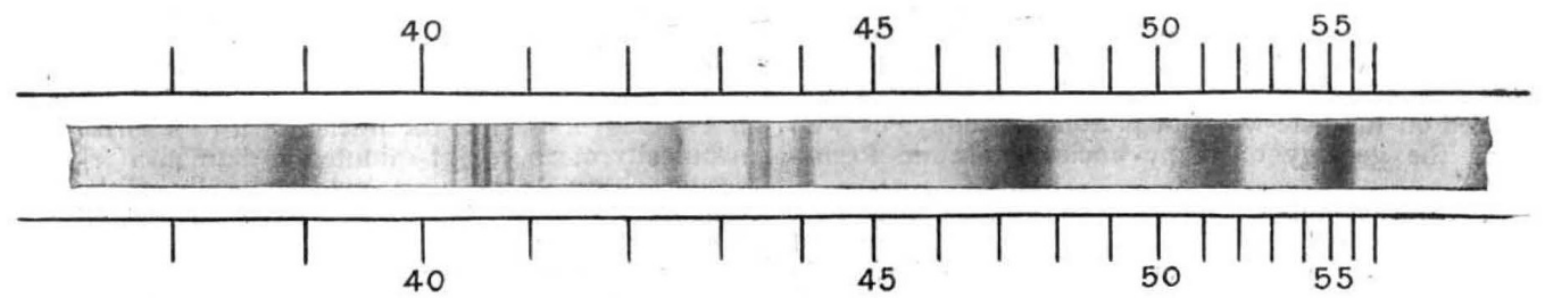

FIG. 2.-Spectrum of Brooks's Comet drawn from a photograph taken at the Madrid Observatory.

The writer has made a comparison of this spectrum with that which was taken of comet Igo7d (Daniel) by Prof. Campbell. While the latter spectrum is on a very much larger scale and rich in detail, it is seen nevertheless that both are very closely identical when allowance is made for the smaller scale. As Daniel's comet was stated by Campbell to show no radiations other than those due to carbon or carbon compounds, NO. 2 I94, VOL. 88$]$
Quantentheorie auf eine Reihe physikalisch-chemische Probleme, by Prof. Nernst; les preuves de la Réalité Moléculaire, by Prof. Perrin; die kinetische Theorie der ideale Gase und die Versuchsresultate, by Prof. Knusden.

A vigorous discussion took place on each of these papers, an abstract of which will ultimately be published. Special interest was taken in the papers deal- 